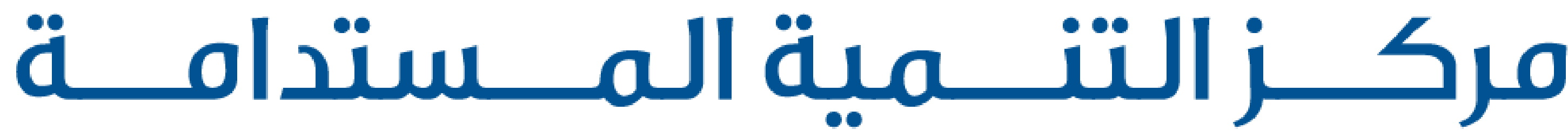

Center for Sustainable Development

Faculty and PostDoc

Energy, Environment \& Resource Sustainability

\section{Production of phycocyanin from marine cyanobacteria in Open raceway pond}

Abdul Quadir, Mohammad; Das, Probir*; Khan, Shoyeb; Thaher, Mahmoud; Al jabri, Hareb m. S.J.

Algal Technology Center, Center for Sustainable Development, College of Arts and Sciences, Qatar University. Doha - Qatar

\section{Abstract \\ - Phycocyanin is one of the major light harvesting accessory pigment present in microalgae and cyanobacteria. \\ - This water-soluble pigment protein exhibits antioxidant, anti-inflammatory, and neuroprotective effects. Application of this pigment also been used in dietary nutritional supplements in many food nutraceutical, cosmetic, and biotechnology industries. \\ In the present study phycocyanin was extracted from locally isolated marine cyanobacteria Geitlerinema \\ Geitlerinema sp. showed a higher growth during the summer perioed of $0.75 \mathrm{~g} / \mathrm{L}$ and $0.54 \mathrm{~g} / \mathrm{L}$ \\ Similarly the maximum Phycocyanin obtain was up to $7.1 \%$ in during summer period.}

\section{Background Study}

High-value compounds with nutraceutical property from microalgae attract many food and biotechnology industries. (C.Bermudez et al., 2015)

Phycocyanin producing strains were wildly studied for their functional property, which has various applications in food, drug, and medicine, and for cosmetics. (R.Thangam et al., 2013)

Often due to the overall costly production process, alternative sources of growth media and harvesting technics nutrient sources such as seawater and nutrients from a different waste industrial stream can be used. (P.Das et al., 2019).

\section{Objectives of the study}

The objective of this research is to find out the seasonal productivity of phycocyanin production in outdoor raceway tanks.

\section{Methodology}

Outdoor Cultivation:

- Geitlerinema sp. grown outdoor when the maximum light intensity was $2400 \mu \mathrm{mol} E / \mathrm{m}^{2} / \mathrm{s}$, and maximum temperature of $48^{\circ} \mathrm{C}$ during summer and

Geitlerinema sp were grown in $1000 \mathrm{~L}$ raceway tanks; the culture depth was maintained to $20 \mathrm{~cm}$ while the evaporation water loss was balanced by adding seawater.

Due to added seawater with time salinity was increasing

Nutrients guillard $10 \times \mathrm{f} / 2$ media were added for this strain.

Pure $\mathrm{CO} 2$ were added to maintain the culture $\mathrm{pH}$ in the open tanks.

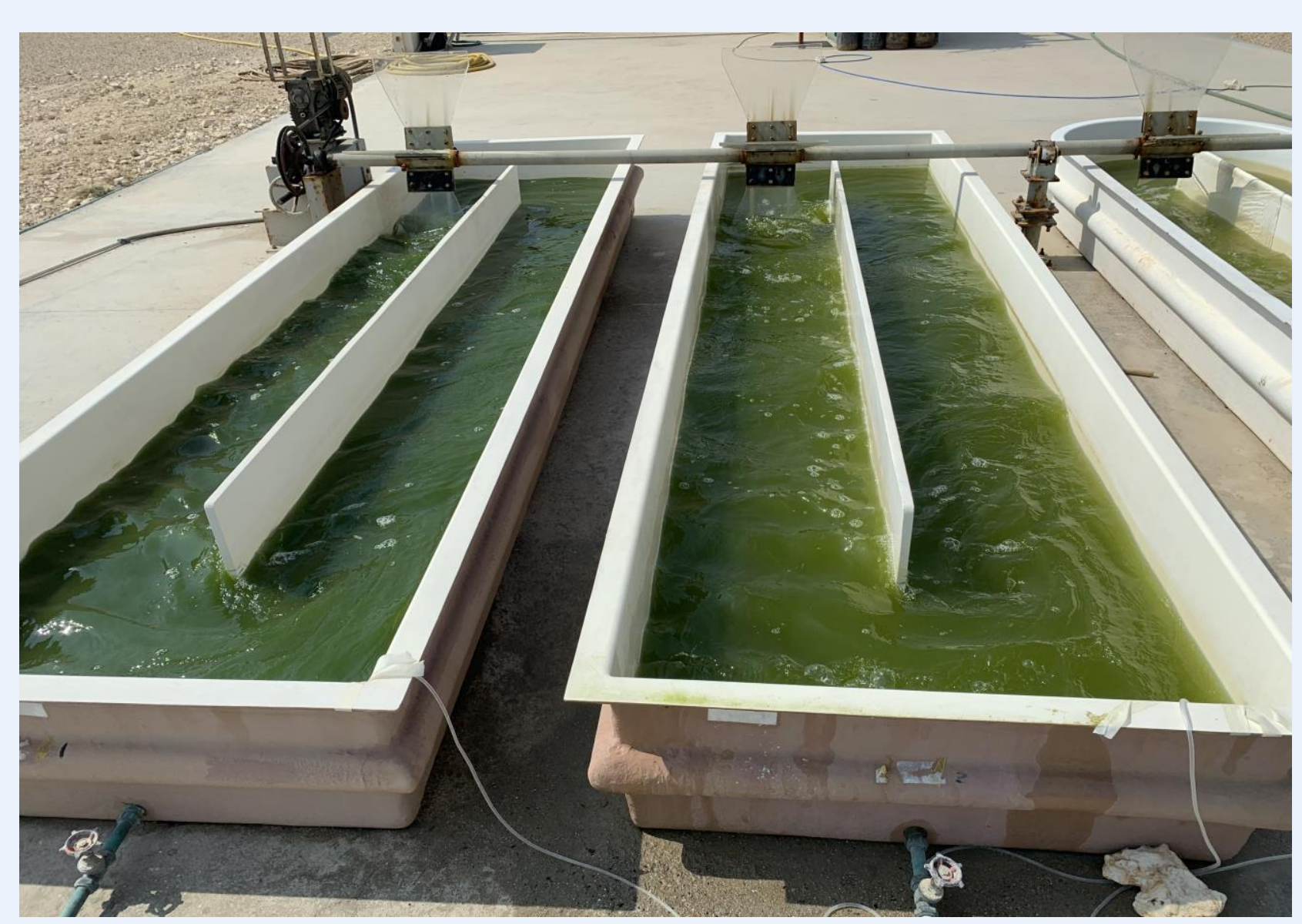

Figure:2a Geitlerinema sp. Growth in 1000 L (during summer)

\section{Harvesting Method:}

All the experiments were conducted with $1000 \mathrm{~L}$ culture and the both of the strain were harvested with TFF unit.

Harvesting was done twice, using a mass filter shown below.

1 liters of culture were collected and centrifuge daily to calculate biomass density.

Phycocyanin Extraction

Harvesting: $2 \times 10 \mathrm{~mL}$ of each culture was centrifuged in $15 \mathrm{~mL}$ falcon tubes for 10 minutes at $5000 \mathrm{RPM}$. Supernatant was discarded, and pellet was stored at $-80^{\circ} \mathrm{C}$ until further processing (20 hours)

thawed pellets were re-suspended in $5 \mathrm{~mL}$ of

Phosphate buffer

Samples were placed in $-20^{\circ} \mathrm{C}$ for 2 hours - when after 2 hours the samples had not completely frozen yet, placed them in $-80^{\circ} \mathrm{C}$ for $\mathbf{2}$ more hours until solid Removed samples from $-80^{\circ} \mathrm{C}$, covered in Aluminum foil (to keep dark), and placed in $4^{\circ} \mathrm{C}$. After20 hours, vortexed the samples and C.C. Aft $1{ }^{\circ} \mathrm{C}$ After $48 \mathrm{~h}$, centrifuged the samples ( $30 \mathrm{~min}$ at $5000 \mathrm{RPM}$ ), and measure OD 620 and 750 of the supernatant

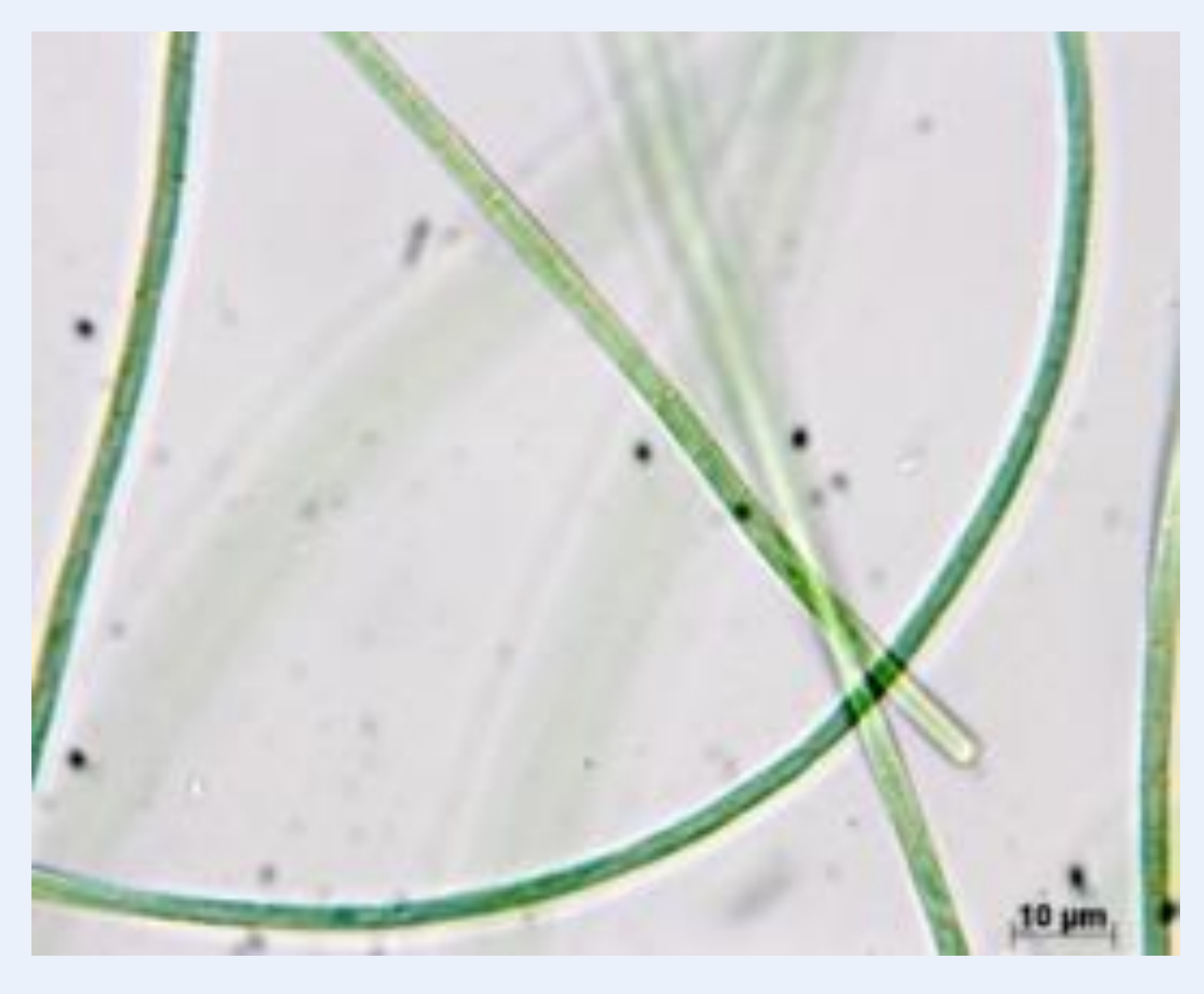

Figure:1 Geitlerinema sp. 100x magnification

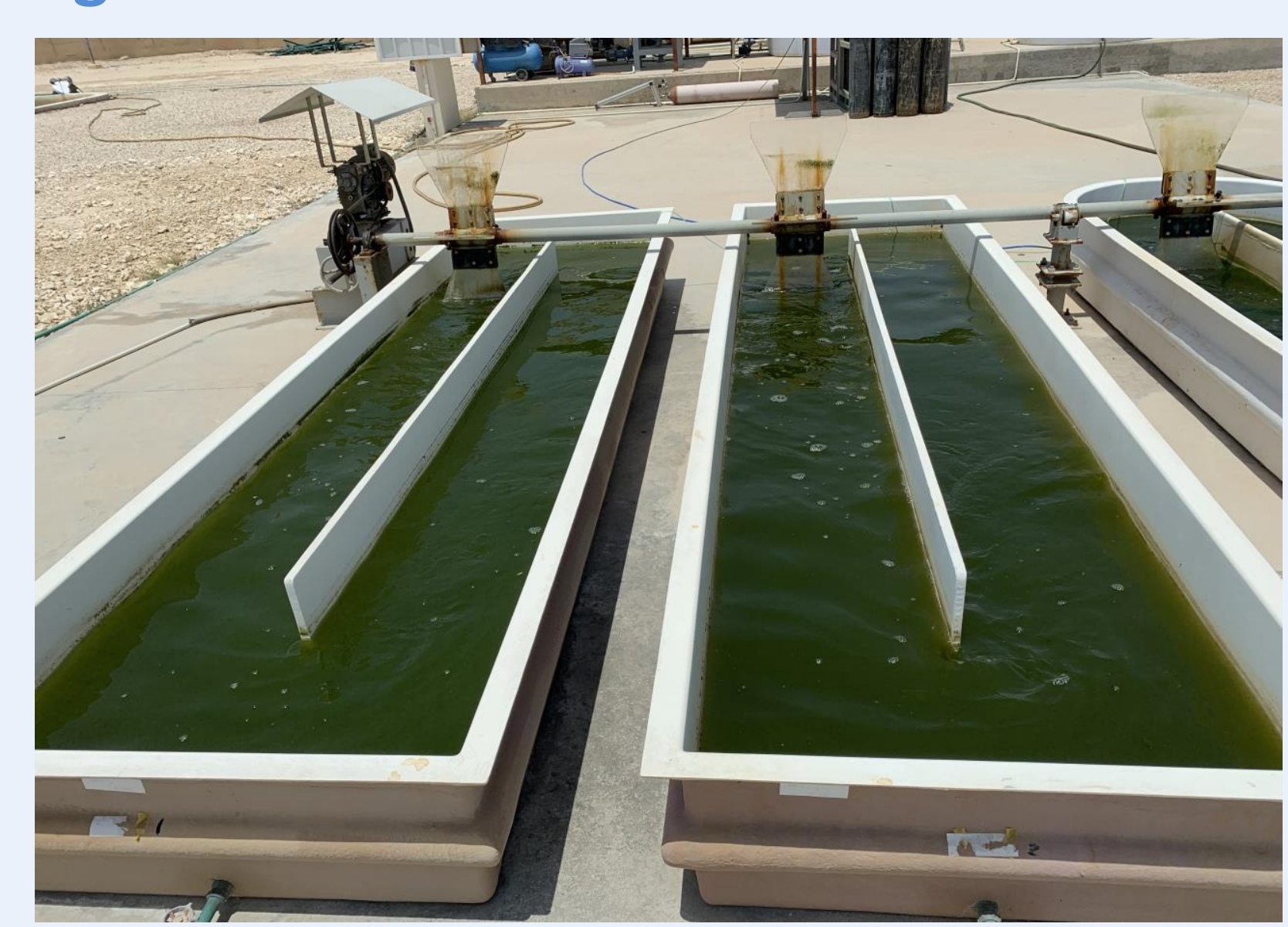

Figure:2b Geitlerinema sp. Growth in $1000 \mathrm{~L}$ (during winter)

Phycocyanin concentration was calculated by Lawrenz et al., (2011) formula. Given below.

$C=\{A / \varepsilon d\}^{*} M W^{*}\{V($ buffer $) / V($ sample $)\} * 10^{\wedge} 6$

$\underline{\mathbf{C}}=$ Phycocyanin Concentration $(\mu \mathrm{g} / \mathrm{L}) ; \underline{\mathbf{A}}=$ Scatter corrected Absorbance (620-750)

$\underline{\varepsilon}=$ molar extinction coefficient PC $(1900000 \mathrm{~L} / \mathrm{mol} / \mathrm{cm})$ $\underline{\mathbf{d}}=$ path length of cuvette $(1 \mathrm{~cm})$

MW Molecular weight $(264000 \mathrm{~g} / \mathrm{mol})$

$\underline{\mathbf{v}}$ buffer Volume of buffer $(0.005 \mathrm{~L})$

V sample Volume of sample (0.01 L)

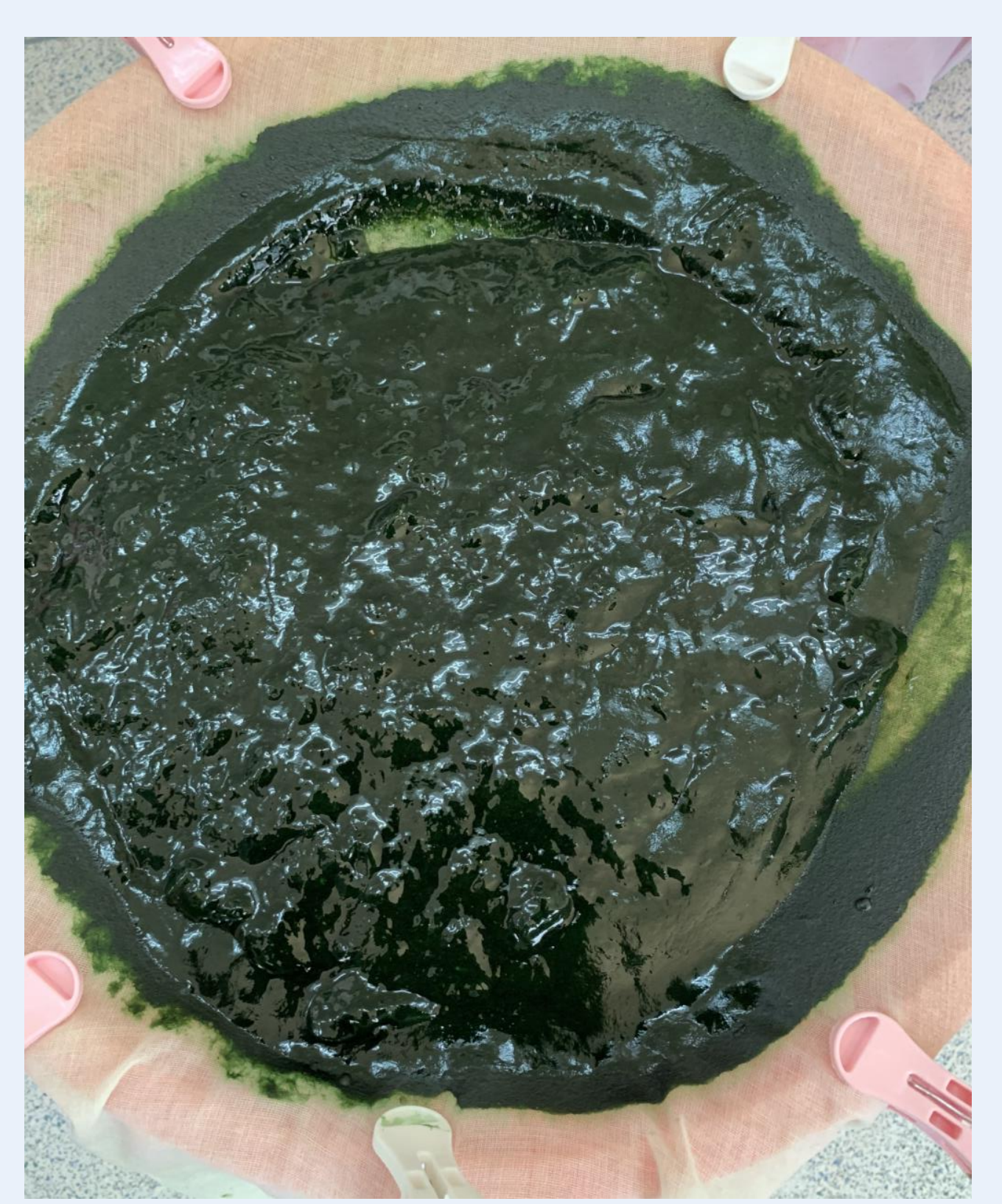

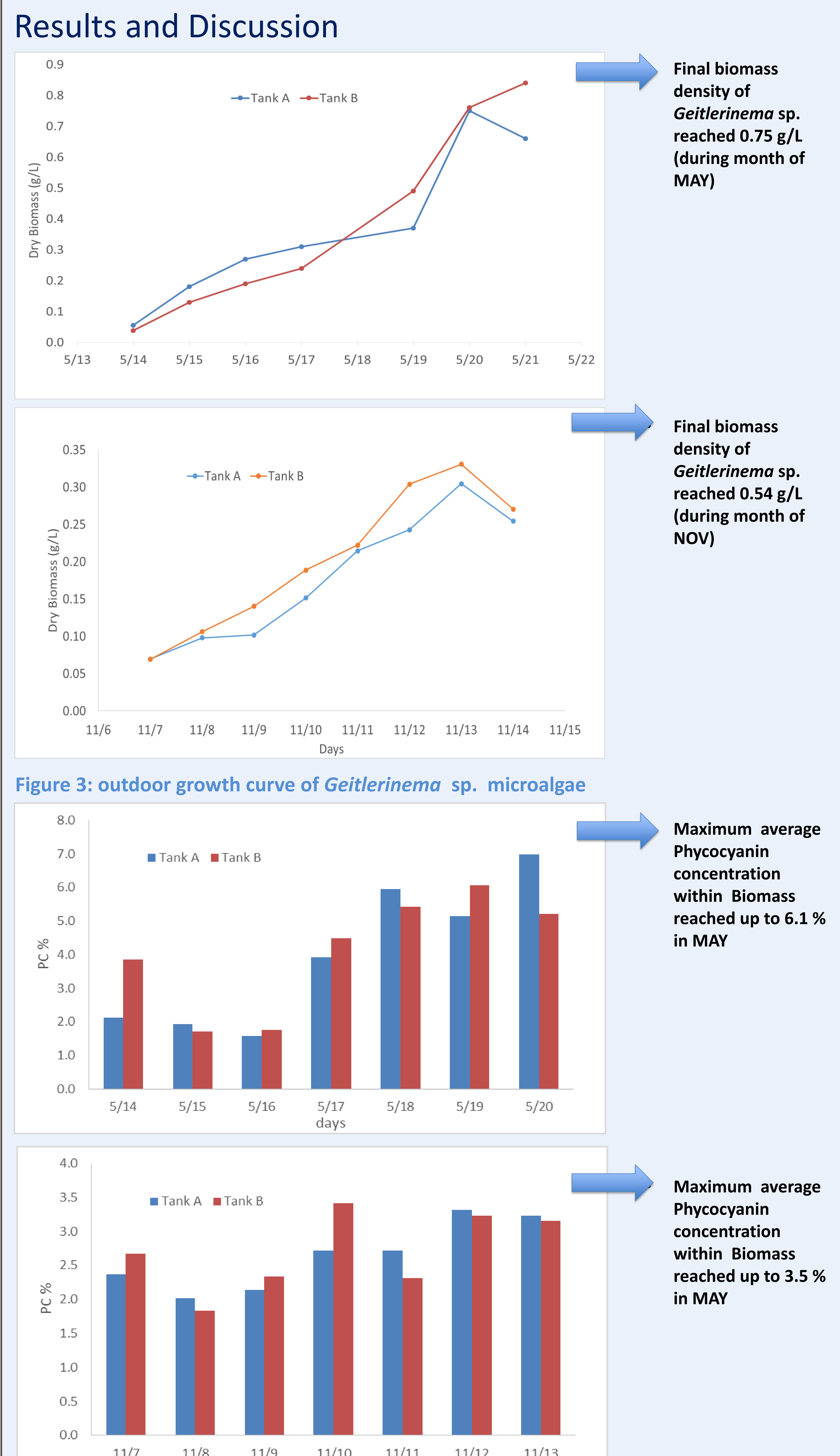

Figure 4: Phycocyanin concentration in Geitlerinema sp.

\section{Conclusion}

- Maximum Cell Phycocyanin concentration was obtain during the month of May.

Overall areal productivity was also observed higher during May, were average ambient temperature ranged from 28 to $39^{\circ} \mathrm{C}$.

Acknowledgment:

The authors would like to acknowledge the support of CSD Team and Qatar National Research Fund (QNRF) for providing the funding (under grant NPRP8-646-2-272) for this study.

\section{References}

Cuellar-Bermudez SP, Aguilar-Hernandez I, Cardenas-Chavez DL, (2015) Extraction and purification of highvalue metabolites from microalgae: Essential lipids, astaxantin and phycobiliproteins. Microb Biotechnol, 8(2) $190-209$

Thangam R, Suresh V, Princy AW, et al. (2013) C-Phycocyanin from Oscillatoria tenuis exhibited an antioxidan and in vitro antiproliferative activity through induction of apoptosis and G0G1 cell cycle arrest. Food Chem, $140,262-272$.

Das, P., Thaher, M., Khan, S., AbdulQuadir, M., \& Al-Jabri, H. (2019). The effect of culture salinity on the harvesting of microalgae biomass using pilot-scale tangential-flow-filter membrane. Bioresource technology, 293, 122057.

Lawrenz, E, Fedewa, E. J, \& Richardson, T. (2011). Extraction protocols for the quantification of phycobilins in aqueous phytoplankton extracts. Journal of Applied Phycology, 23(5), 865-871. 